\title{
Effect of transgenic cotton continuous cropping on soil bacterial community
}

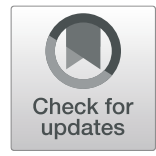

\author{
Wen-hui Tian ${ }^{1 \dagger}$, Xiao-long $\mathrm{Yi}^{1+}$, Shan-shan Liu ${ }^{1,2+}$, Chao Zhou ${ }^{1}$ and Ai-ying Wang ${ }^{1 *}$
}

\begin{abstract}
Purpose: In agricultural practices, continuous cultivation of genetically modified crops with high commercial value has a definite impact on soil microbial diversity. Soil microorganisms directly define the operational degree and function realization of the soil ecosystem. To understand the safety of environmental release, we studied the effects of continuous cropping of transgenic cotton on the diversity of bacterial communities in the rhizosphere soil.

Methods: We have applied a high-throughput sequencing method and compared the bacterial community structure as well as diversity of rhizosphere soil of the transgenic cotton line (25C-1) and its parent cotton line (TH2).

Result: Structural analysis of the bacterial community showed that Arthrobacter and Sphingomonas are significantly enriched after continuous cropping of transgenic cotton lines and had a positive impact on the soil's ecological environment. Interestingly, parameters of the physical and chemical properties of soil used for the continuous cropping of the two cotton lines for 3 consecutive years show no detectable change, other than total nitrogen. Notably, Spearman's correlation analysis suggests that total nitrogen is the key environmental factor that affects the bacterial community of the soil used to cultivate the transgenic cotton.

Conclusion: We did not find a notable difference in species diversity between the two samples. However, the proportions of beneficial bacteria (Arthrobacter and Sphingomonas) increased and the total nitrogen content has changed in 3 years. These results provide necessary insights into the function and role of bacteria in transgenic cotton. This study will help future investigators assess the potential ecological risks of genetically modified plants.
\end{abstract}

Keywords: Transgenic cotton rhizosphere soil, High-throughput sequencing, Bacterial community, Environmental safety assessment of transgenic crops

\section{Introduction}

The global production of genetically modified crops has grown profoundly from 1.7 million hectares in 1996 to 191.7 million hectares in 2018 (Babar et al. 2019). The agriculture practices with commercial transgenic crops, such as cotton (a leading cash crop) and maize (Trivedi et al. 2012), have brought enormous economic benefits worldwide (Guo et al. 2018). However, world average cotton yield in 2005 was estimated at $650 \mathrm{~kg}$ lint ha ${ }^{-1}$, a $73 \%$ loss to various stresses (comparable to those values

\footnotetext{
* Correspondence: way-sh@126.com

'Wen-hui Tian, Xiao-long Yi and Shan-shan Liu contributed equally to this work.

${ }^{1}$ College of Life Sciences, Shihezi University, Shihezi 832000, China Full list of author information is available at the end of the article
}

published for other crops). Among all stresses, the main factors affecting cotton yield are drought and salt stress, and improving the tolerance of cotton to these two abiotic stresses is currently the most urgent task (Saranga et al. 2009). A recent report demonstrates that under stress conditions, the Arabidopsis transcription factors $C B F / D R E B 1$ bind to $C R T / D R E$ to activate the transcription of its downstream genes, COR (Randall and Yamasaki 2016). This enhances the ability of the plants to resist various abiotic stress such as low temperature, drought, and high salt (Verslues et al. 2006).

Like the advancement of any other technology, the question of environmental risks associated with transgenic plants remains to be answered. The increased worldwide commercial cultivation of genetically modified crops in

(c) The Author(s). 2020 Open Access This article is licensed under a Creative Commons Attribution 4.0 International License, which permits use, sharing, adaptation, distribution and reproduction in any medium or format, as long as you give appropriate credit to the original author(s) and the source, provide a link to the Creative Commons licence, and indicate if changes were made. The images or other third party material in this article are included in the article's Creative Commons licence, unless indicated otherwise in a credit line to the material. If material is not included in the article's Creative Commons licence and your intended use is not permitted by statutory regulation or exceeds the permitted use, you will need to obtain permission directly from the copyright holder. To view a copy of this licence, visit http://creativecommons.org/licenses/by/4.0/. 
the past 20 years is likely to have a profound impact on soil microbial communities (Lilley et al. 2006; Hutchison et al. 2010; Lu et al. 2012). Multiple lines of evidence have shown that transgenic plants affect the soil microbial communities, especially rhizosphere bacteria (Koskella and Stotzky 1997; Knox et al. 2007; Jepson et al. 2010; Trivedi et al. 2012). The foreign genes in transgenic crops may remain in the soil through root exudates or defoliation. This may lead to the change of soil microbial communities, and the physical and chemical properties of soil will change accordingly. Moreover, inflicted changes may also affect the availability and release of soil nutrients (DeAngelis et al. 2009; Uroz et al. 2010). Therefore, the effect of transgenic plants on soil microbial communities is of great significance for scientific assessment to evaluate its potential ecological risks in the future.

Soil microorganisms play a central role in the biogeochemical cycle of nutrient and organic matters. This is mainly caused by decomposition of the organic materials in the soil that essentially maintains a stable agricultural ecosystem (Van der Heijen et al. 2008). Most plants have symbiotic relationships with soil microbes (bacteria and fungi) during their growth and development. Soil bacteria are the most abundant and widely distributed among soil microorganisms. The plant grows in close association with a bacterial community that lives and thrives in soil around the surface (rhizosphere) or inside their roots (endosphere) (Berg et al. 2014). In particular, plants are known to define the composition of their rhizospheric bacterial microbiome (Berendsen et al. 2012). Thus, alteration in the composition and structure of the soil microbial communities or composition is reflected as deteriorating soil quality, and thus also plant health (Raza et al. 2016).

The rhizosphere was defined over 100 years ago as the zone around the root where microorganisms and processes important for plant growth and health are located (Bakker et al. 2013). Any changes in the physical and chemical properties of rhizosphere soil can reflect the influence of plants on it (Yang et al. 2017). Root morphology and distribution of crops affect the structure of the soil microbial community, while root exudates directly affect the soil microbial community abundance (Nie et al. 1997). The quality and growth pattern of the plants indirectly reflect the quality of the soil (Qiao et al. 2017). Therefore, it is more important to investigate the effect of transgenic crops on the structure and diversity of soil microbial communities.

High-throughput sequencing technology can be used to obtain comprehensive information about soil microbial structure, diversity, and function. This can also be used for the in-depth assessment of the changes in soil microbial communities over time. In the present work, the soil physical and chemical properties and soil microbial diversity of transgenic $(25 \mathrm{C}-1$, possessing the CBF1 gene) as well as non-transgenic cotton (TH2) have been studied. The study was aimed to (1) explore the correlation between the changes in physical and chemical properties of soil and the relative abundance of soil microbial communities in soil used to cultivate transgenic cotton, (2) study the effects of continuous cropping of transgenic cotton on the microbial community of plant rhizosphere soil, and (3) identify the dominant bacterial population in the continuous cropping of genetically modified cotton. The study provides considerable insights into the impact of genetically modified cotton on soil microbial communities that may also help policymakers in evaluating environmental safety threats of commercialized genetically modified crops.

\section{Materials and methods}

\section{Site description, field experiment, and soil sampling}

The experiments in the present article were performed at the Shihezi University Experimental Base $\left(44^{\circ} 20^{\prime} \mathrm{N}\right.$, $85^{\circ} 50^{\prime} \mathrm{E}$ ), in the Xinjiang Uygur Autonomous Region, China. The field site is located in the early maturing or extremely early mature cotton planting ecological zone of the northern foothills of the Tianshan Mountains in Xinjiang. It is located in the North Temperate Zone that has a temperate continental plateau climate. The warmest month of the year is July, with a mean temperature of 25.2 to $26.2{ }^{\circ} \mathrm{C}$, and the maximum goes up to $42.2^{\circ} \mathrm{C}$. The coldest month of the year is January, with a mean temperature of -18.6 to $-15.5^{\circ} \mathrm{C}$, and a minimum temperature drops down to $-37.8^{\circ} \mathrm{C}$. A total of around 168 171 days in a year are reported frostless in the region. Moreover, average annual rainfall and annual evaporation in the region are recorded around $213 \mathrm{~mm}$ and $1537 \mathrm{~mm}$, respectively.

TH2 was used as the recipient cotton cultivar. The transgenic cotton line $25 \mathrm{C}-1$ was developed in the Key Laboratory of Agricultural Biotechnology of Shihezi University using a pollen tube pathway method on $\mathrm{TH} 2$. The cotton field adopts a random block design which has 3 rows per plot, and each plot covers an area of $11.25 \mathrm{~m}^{2}$, with about 300 plants and a spacing of $10 \mathrm{~cm}$. The 3 plots were planted as 3 replicates (Liu et al. 2019).

The rhizosphere soil samples were collected for 3 consecutive years precisely on July 15 . The soil samples were collected following Riley and Barber's shake method (Riley and Barber 1970). In 3 repeated random plots planted with different cotton materials, five sample points were selected from each plot using an S-shaped distribution for sampling. A boring auger with an inner diameter of $6.0 \mathrm{~cm}$ was vertically inserted into the soil, which collected rhizosphere soil from the bottom of the interplanting lines $(5-20 \mathrm{~cm})$. The acquired mixed samples were sieved $(4 \mathrm{~mm}, 5$ mesh). The sieved samples 
were stored at $4{ }^{\circ} \mathrm{C}$ before being used in the laboratory for further experiments.

\section{Soil physical and chemical properties}

The properties of the soil samples collected over time were analyzed following the previously described methods (Hungria et al. 2013). Organic matter (OM) and total nitrogen (TN) of the soil samples were quantified using $\mathrm{KCr}_{2} \mathrm{O}_{7}$ and $\mathrm{HClO}_{4}-\mathrm{H}_{2} \mathrm{SO}_{4}$ digestion methods, respectively. Available phosphorus (AP) was measured by Mo-Sb colorimetric method from the soil samples extracted using $\mathrm{NaHCO}_{3}$. Atomic absorption spectrometry was performed over the samples extracted using $\mathrm{NH}_{4} \mathrm{OAc}$ to quantify the available potassium (AK) in the soil. The $\mathrm{pH}$ and electrical conductivity (EC) of the soil samples were determined in a 1:5 $(\mathrm{w} / \mathrm{v})$ suspension of soil in water.

\section{DNA extraction, PCR amplification, and Illumina MiSeq sequencing}

Total genomic DNA was extracted from samples using PowerSoil ${ }^{\circ}$ DNA Isolation Kit and as instructed by the manufacturer (Mo Bio Laboratories, Solana Beach, CA, USA). The purified DNA was subjected to $1 \%$ agarose gels to measure the quality of the soil samples.

The DNA samples were diluted with $\mathrm{ddH}_{2} \mathrm{O}$ to obtain dilutions of $1 \mathrm{ng} / \mu \mathrm{l}$. The $16 \mathrm{~S}$ rRNA genes of the $\mathrm{V} 4$ region were amplified using 515F-806R (5' -GTGCCAGCMGCC GCGGTAA-3' and 5'-GGACTACHVGGGTWTCTAAT$\left.3^{\prime}\right)$ primer pairs having barcodes. All PCR reactions were carried out using Phusion ${ }^{\circ}$ High-Fidelity PCR Master Mix (New England Biolabs).

Sequencing of the DNA samples for further analysis was performed on an Illumina HiSeq 2500. Paired-end reads were assigned to samples based on their unique barcode followed by a truncation of the barcodes and primer sequences (Magoč and Salzberg 2011). The raw sequencing data were merged using FLASH (v1.2.7). Chimeras were removed using Mothur, while the short sequences from the spliced strands, for quality control and filtering, were obtained effectively by splicing fragments (clean tags). Thereafter, based on the valid data, UIIust and Uclust methods (Edgar 2013) were used for the OTU (operational taxonomic unit) clustering and species classification analysis that is based on the $97 \%$ sequence similarity (Bokulich et al. 2013). The RDP classifier was used to annotate taxonomic information for representative sequences of each OTU. An in-house Perl script was developed and used to analyze $\alpha$ - and $\beta$ diversity (Zhang and Wang 2017).

\section{Statistical analysis}

The physicochemical data were analyzed by one-way ANOVA followed by Duncan's multiple range tests using the SPSS Statistical Software Package ver. 26 (SPSS Inc., USA). The significance level of the data was set at $P$ $<0.05$. In $\alpha$-diversity analysis, rarefaction curves, Chao1, and Shannon's index were generated to reflect community richness and their diversity respectively, whereas the comparative analysis of microbial community composition of different samples was assessed using $\beta$-diversity. The degree of bacterial differences between samples was analyzed based on non-metric multi-dimensional scale (NMDS). We also performed an unweighted UniFrac distance matrix for UPGMA (unweighted pair-group method with arithmetic mean) cluster analysis and integrated the clustering results with the relative abundance of each sample. Spearman's correlation heat map prepared to reflect a relationship between soil fungal community composition and environmental factors.

\section{Results}

\section{Soil physical and chemical properties}

The physical and chemical properties of soil are shown in Table 1 . The parameters, namely $\mathrm{pH}, \mathrm{EC}, \mathrm{OM}, \mathrm{AP}$, and $\mathrm{AK}$, of the soil samples from the two cotton lines were not significantly different $(P>0.05)$. Interestingly, a significant difference was observed in the TN values of the soil samples. After the first year of planting, the TN values of $\mathrm{TH} 2$ and $25 \mathrm{C}-1$ were $0.33 \pm 0.06$ and $0.27 \pm 0.12$, and then increased to $0.61 \pm 0.10$ and $0.44 \pm 0.04$ in the second year $(P<0.05)$.

\section{Soil bacteria community and diversity}

A total of 544,645 high-quality reads were obtained from six samples using Illumina MiSeq sequence analysis. A total of 32,820 OTUs were also observed at a $97 \%$ similarity (rhizosphere soil sample of transgenic cotton is denoted by SS1, while the recipient cotton rhizosphere soil sample by SS2). The bacterial OTUs were assigned with 54 phyla, 110 classes, 211 orders, 364 families, and 516 genera.

Annotation of the soil microbial data obtained suggests that 10 predominant phyla are predominantly present in the sample. Subsequent analysis of the data indicates that Proteobacteria, Acidobacteria, Actinobacteria, Gemmatimonadetes, Bacteroidetes Planctomycetes, Chloroflexi, Verrucomicrobia, Nitrospirae, and Firmicutes precisely share 26.53, 22.34, 13.41, 13.54 5.51, 4.14, 3.57, 2.91, 1.47, and $1.20 \%$ of the total microbial predominance respectively (Fig. 1). Furthermore, a heat map was prepared for the abundance in each sample (Fig. 2). It should be noted that the top 35 genera were selected for clustering from the two levels of species and samples. Arthrobacter, Blastocatella, unidentified_Gemmatimonadetes, Sphingomonas, Gemmatimonas, Massilia, Haliangium, Gaiella, Solirubrobacter, and Bryobacter presents the first 10 bacterial genera that precisely share $1.66,1.39,1.69,1.33,1.20,0.73,0.83,0.75,0.69$, and $0.81 \%$ of the total abundance (Fig. 2). 
Table 1 The basic physical and chemical properties of the soil

\begin{tabular}{|c|c|c|c|c|c|c|c|}
\hline Years $^{a}$ & Treatment $^{b}$ & $\mathrm{PH}$ & $\mathrm{EC}\left(\mathrm{ms} \mathrm{m}^{-1}\right)$ & $\mathrm{OM}\left(\mathrm{g} \mathrm{kg}^{-1}\right)$ & $\mathrm{TN}\left(\mathrm{g} \mathrm{kg}^{-1}\right)$ & AP $\left(\mathrm{mg} \mathrm{kg}^{-1}\right)$ & $\mathrm{AK}\left(\mathrm{mg} \mathrm{kg}^{-1}\right)$ \\
\hline \multirow[t]{2}{*}{1} & $\mathrm{TH} 2$ & $7.88 \pm 0.08 a$ & $0.21 \pm 0.10 \mathrm{a}$ & $8.74 \pm 1.17 \mathrm{a}$ & $0.33 \pm 0.06 b c$ & $15.51 \pm 9.35 a$ & $286.16 \pm 47.16 \mathrm{a}$ \\
\hline & $25 C-1$ & $7.84 \pm 0.32 a$ & $0.22 \pm 0.10 \mathrm{a}$ & $8.68 \pm 5.17 a$ & $0.27 \pm 0.12 c$ & $13.22 \pm 4.25 \mathrm{a}$ & $276.36 \pm 77.25 \mathrm{a}$ \\
\hline \multirow[t]{2}{*}{2} & $\mathrm{TH} 2$ & $7.94 \pm 0.24 a$ & $0.42 \pm 0.47 a$ & $12.22 \pm 2.56 \mathrm{a}$ & $0.61 \pm 0.10 a$ & $20.22 \pm 3.71 \mathrm{a}$ & $322.05 \pm 37.59 a$ \\
\hline & $25 C-1$ & $7.84 \pm 0.28 a$ & $0.44 \pm 0.39 a$ & $12.33 \pm 2.39 a$ & $0.44 \pm 0.04 b$ & $13.90 \pm 5.45 a$ & $302.57 \pm 48.22 \mathrm{a}$ \\
\hline \multirow[t]{2}{*}{3} & $\mathrm{TH} 2$ & $7.50 \pm 0.07 a$ & $0.19 \pm 0.06 a$ & $11.09 \pm 0.39 a$ & $0.39 \pm 0.05 b c$ & $11.08 \pm 2.71 \mathrm{a}$ & $285.48 \pm 41.41 \mathrm{a}$ \\
\hline & $25 C-1$ & $7.67 \pm 0.38 a$ & $0.15 \pm 0.05 a$ & $10.72 \pm 1.45 a$ & $0.28 \pm 0.03 c$ & $10.10 \pm 4.32 \mathrm{a}$ & $248.57 \pm 126.77 a$ \\
\hline
\end{tabular}

The data have been shown as mean \pm SE. Letters following the data indicate significant differences between samples during different sowing years of each cotton line (Duncan's multiple range test was employed, $P<0.05$ )

${ }^{\mathrm{a}} 1,2$, and 3 represent continuous cropping during the $1 \mathrm{st}$, 2nd, and $3 \mathrm{rd}$ year, respectively

${ }^{\mathrm{b}}$ Acceptor cotton rhizosphere soil (TH2) and rhizosphere soil of transgenic cotton (25C-1)

All the sparse curves obtained using QIIME pipeline with a $97 \%$ sequence similarity tend to be close to the saturation platform. This indicates that the number of sequencing reads in each sample was reasonable; SS1 and SS2 are equally rich in terms of the species diversity and uniformity that is also apparent in terms of their high coincidence values (Fig. 3).

\section{Beta diversity analysis}

Non-metric multi-dimensional scale (NMDS) is a classification method suitable for ecological research that can be explained by a nonlinear model. It reliably reflects the nonlinear trend of data that help to overcome the shortcomings of linear models (e.g., PCA, PCoA). The NMDS model relies on the distance between points in multi- dimensional space to reflect the degree of difference between individual samples (Fig. 4). A clustering tree can be constructed to show the similarity between different samples by cluster analysis over them. UPGMA cluster tree structure is denoted on the left, while the species relative abundance distribution map of each sample at the gate level is shown on the right (Fig. 4).

The NMDS variation analysis suggests that SS1 and SS2 are mainly different on the NMDS scale of A-3 and B-3 points (Fig. 4). Unweighted UniFrac cluster analysis of six soil samples exhibited that SS1.1, SS1.2, SS2.1, and SS2.2 were relatively similar. On the contrary, SS1.3 and SS2.3 relate to different branches and show no significant difference in the classification levels of the 10 phyla (Fig. 5).

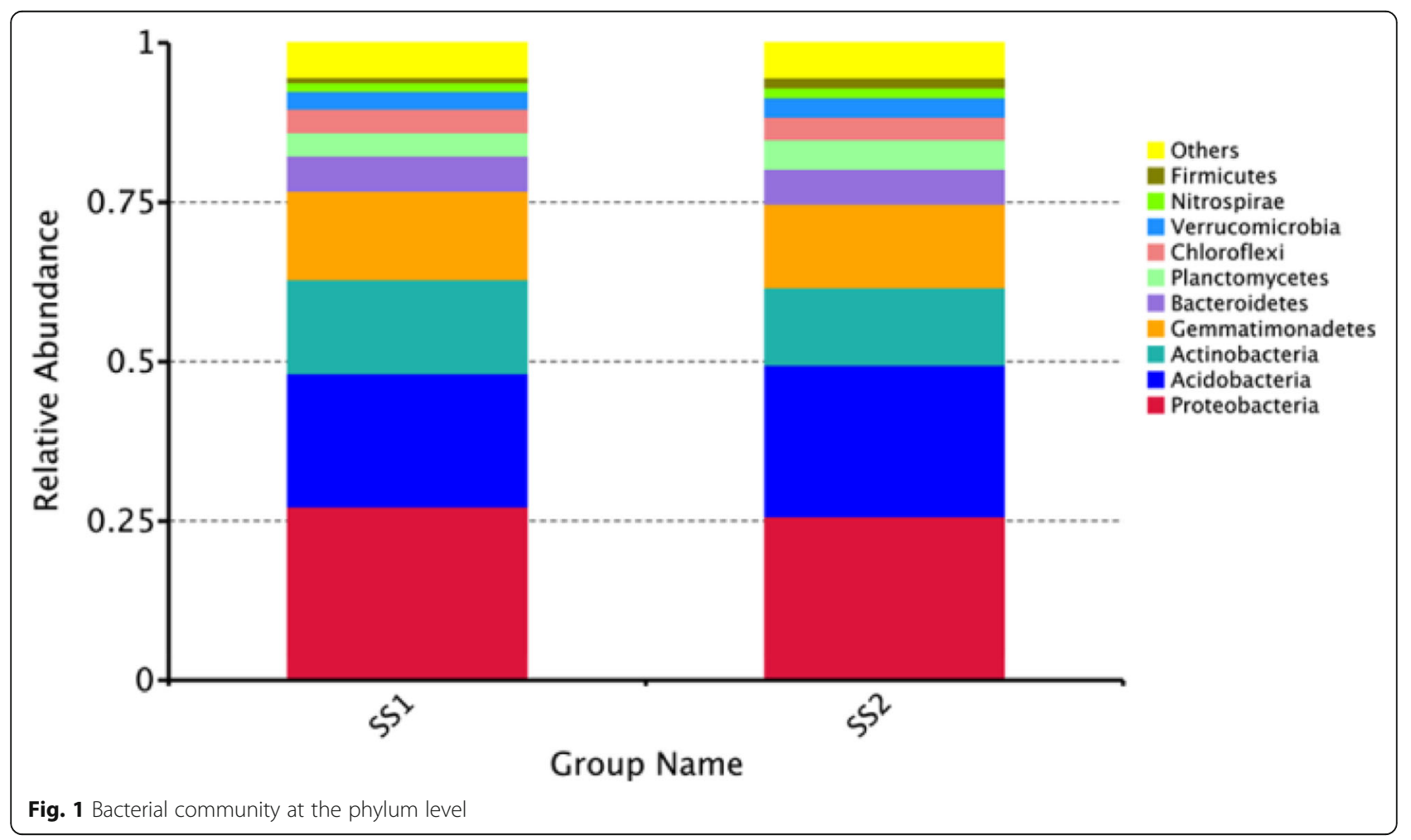



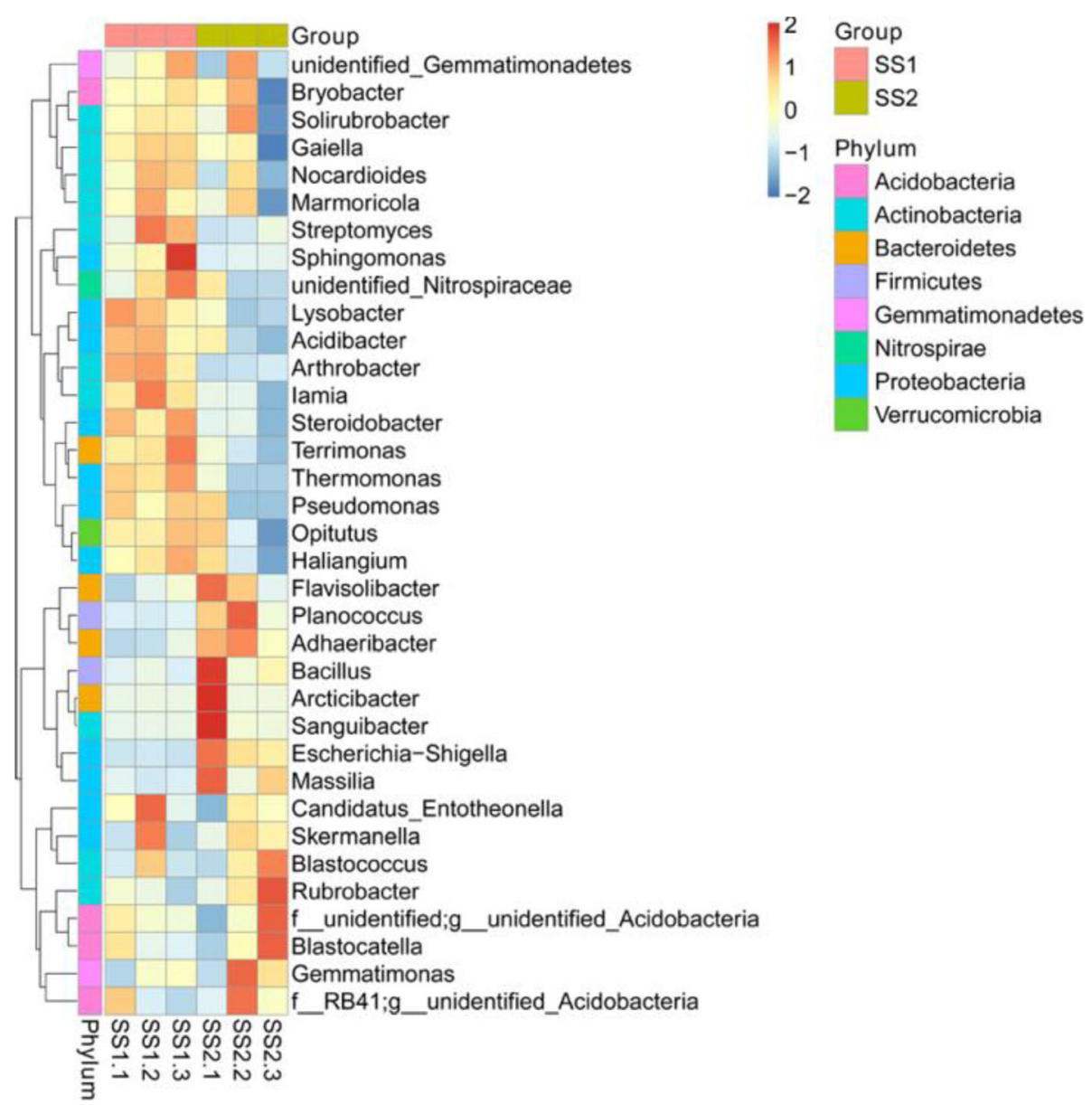

Fig. 2 A generic horizontal heat map of the relative abundance of bacterial communities in six indicated samples

\section{Correlation between environmental data and microbial communities}

We used Spearman's correlation analysis to access the abundance of the top 35 genera identified based on the heat maps (Fig. 6). The results suggest that TN is the most critical environmental factor that significantly affects the soil bacterial community of transgenic cotton. More specifically, TN was correlated negatively with Acidibacter, Lysobacter, and Iamia, while positively with Planococcus and Adhaeribacter bacteria. In addition to the TN, AP was also negatively correlated with Blastococcus and Candidatus Entotheonella. Moreover, the correlation data did not suggest any definitive link between other environmental factors and bacterial communities. Taken these results together, it was confirmed that the microbial communities namely Acidibacter, Lysobacter, Iamia, Planococcus, Adhaeribacter, Blastococcus, and Candidatus Entotheonella were not significantly different after 3 years of continuous cropping of both the transgenic cotton line $25 \mathrm{C}-1$ and its parent cotton line TH2. Moreover, they do not belong to the dominant genus.

\section{Discussion}

Transgenic plants that show herbicide tolerance, salt tolerance, drought tolerance, disease resistance, and insect resistance improved product quality and superior agronomic properties (Liu et al. 2005). Considering the possible environmental consequences of growing genetically modified crops, evaluating the impact of genetically modified crops on soil microorganisms will become an important issue. In this study, the effects of continuous cropping of genetically modified cotton on its soil bacterial community structure and diversity were investigated by high-throughput sequencing technology.

Based on the studies conducted at Central Institute for Cotton Research, Nagpur, it was found that growing $B t$ cotton does not affect the soil biological properties (Velmourougane and Sahu 2013). In this study, our analysis showed that soil TN content significantly differs $(P<$ 0.05 ) (Table 1). Soil TN plays a vital role in controlling soil fertility and crop yield (He et al. 2009). The TN content is a dynamic parameter, the level of which in the soil changes with deposition and consumption of nitrogen (Batista et al. 2015). This depends on multiple 


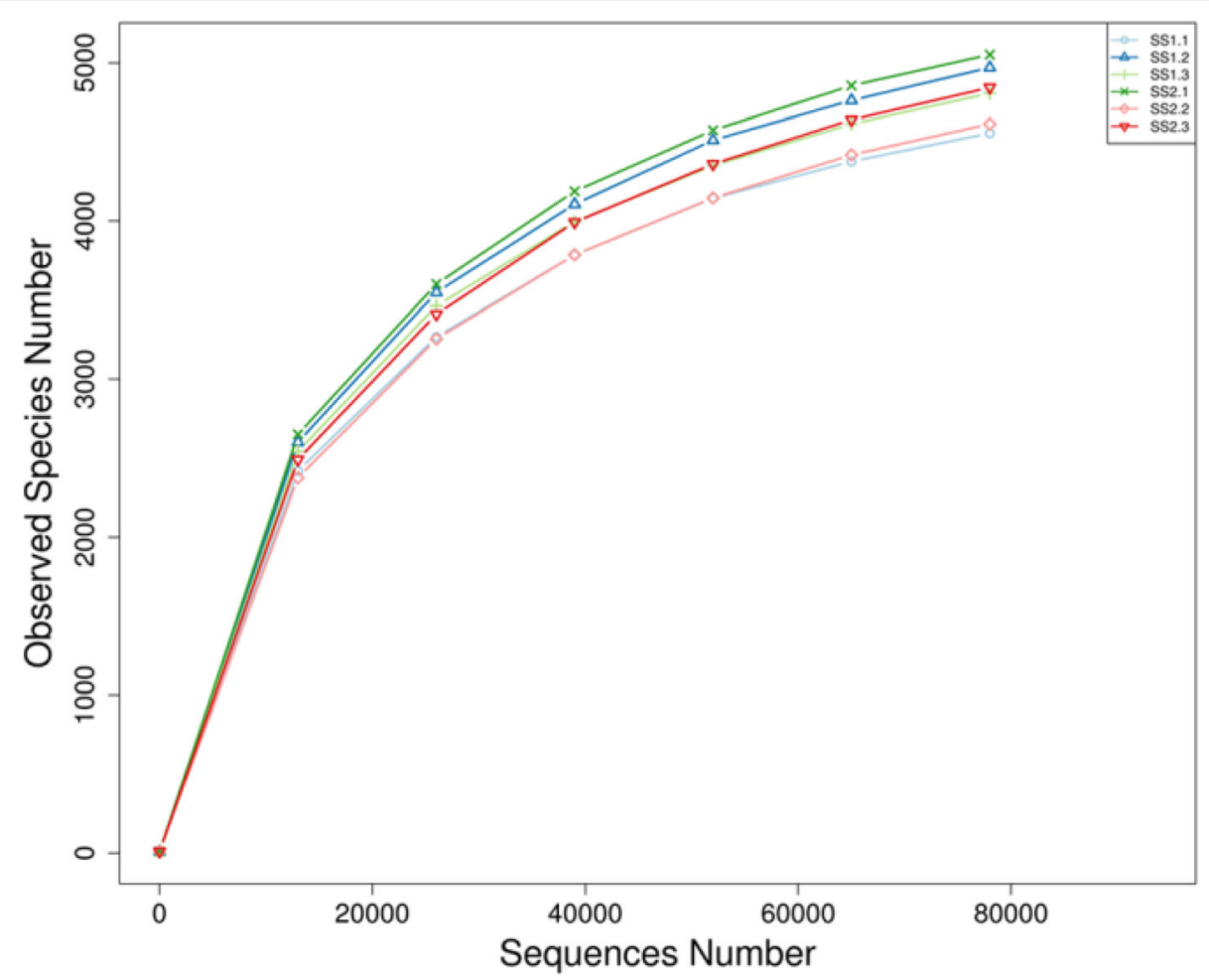

Fig. 3 OTU similarity of each sample with a $97 \%$ species diversity curve

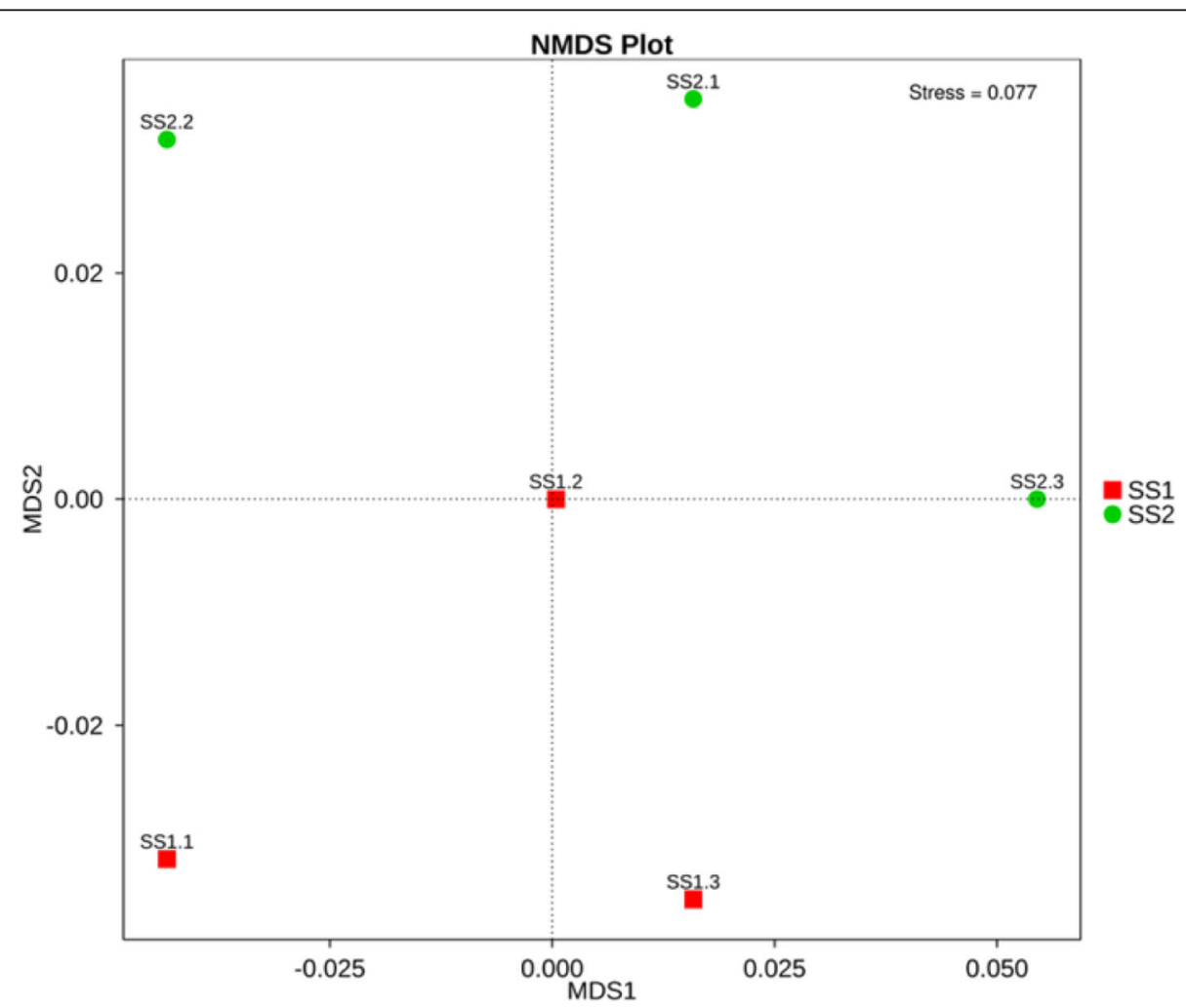

Fig. 4 Non-metric multi-dimensional scaling analysis of species 


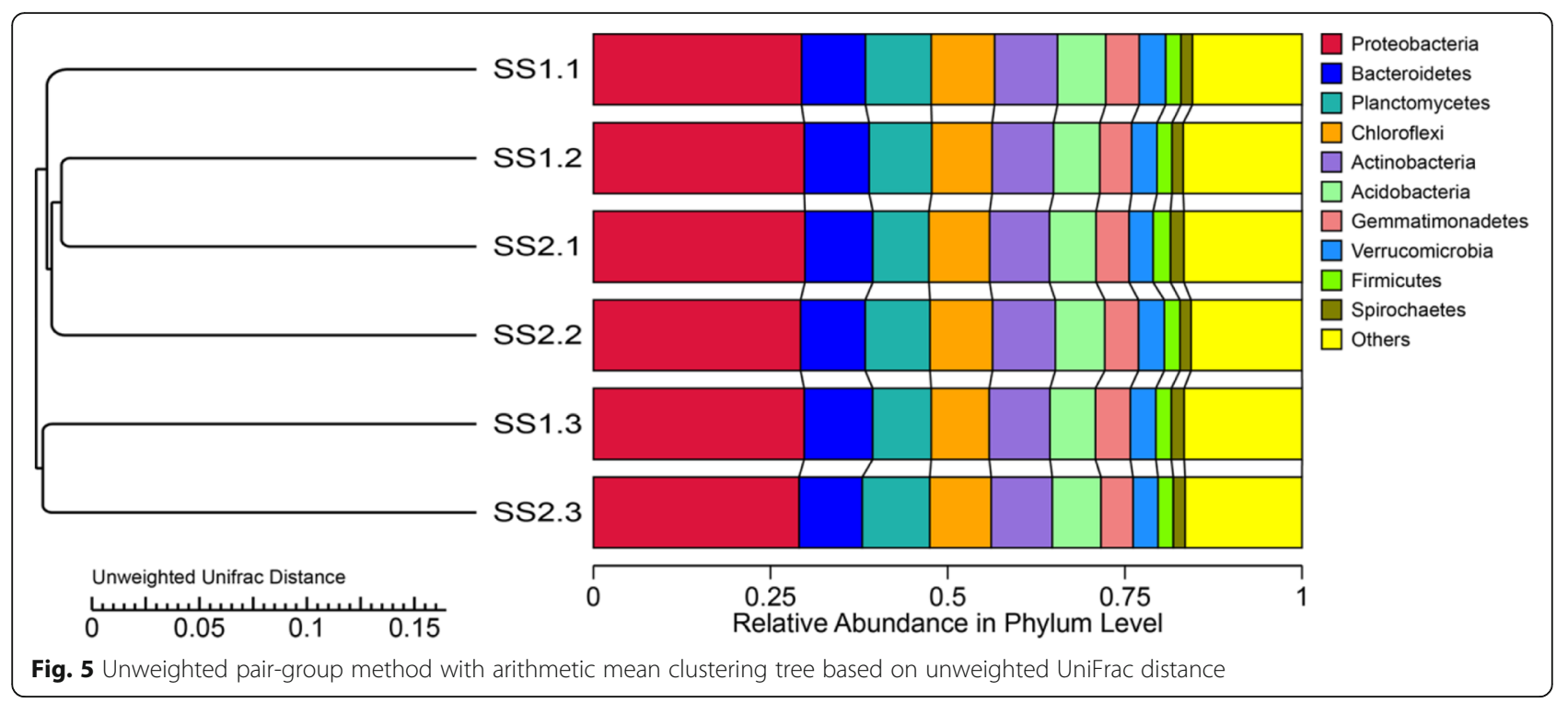

factors, in particular, the nitrogen fixation by plants and hydrolysis of soil organic matter (Wardle 2008). OM is an important constituent of the soil that remains present in trace but is indispensable in maintaining the soil nutrients, physical properties, melting, decomposition, and synthesis of humus (Berg et al. 2014). The results suggest that after the first year of planting, the $\mathrm{OM}$ values of $\mathrm{TH} 2$ and $25 \mathrm{C}$ - 1 were $8.74 \pm 1.17$ and $8.68 \pm 5.17$, and then increased to $12.22 \pm 2.56$ and $12.33 \pm 2.39$ in the second year $(P>0.05)$. The further analysis hinted that the decomposed straw to the cotton field was the main reason for the accumulation of soil organic matter. Interestingly, we did not report any significant difference in $\mathrm{PH}, \mathrm{EC}$, $\mathrm{OM}, \mathrm{AP}$, and $\mathrm{AK}$ in the rhizosphere soil of $\mathrm{TH} 2$ and $25 \mathrm{C}$ 1 during 3 years of continuous cropping $(P>0.05)$. Taken all these results together, we propose that the transgenic line $25 \mathrm{C}-1$ imposes no considerable impact on the physical and chemical properties of the soil and thus may not have any adverse effects on the plant growth cycle or environment, which agrees with the results of previous Btcotton research (Sarkar et al. 2009).

The results clearly showed that the main phyla present in the soil samples were Proteobacteria, Acidobacteria, Actinobacteria, and Gemmatimonadetes, among which Proteobacteria was the most important phylum (Fig. 1), which agrees with the results of Fan et al. (2017). Proteobacteria is a gram-negative bacterium containing nitrogen fixation genes in its genome (Delmont et al. 2018). The proportion of Proteobacteria in rhizosphere soil of $25 \mathrm{C}-1$ cotton strain was found to be higher compared to the TH2 cotton strain (Fig. 1). Notably, the proportion of Actinobacteria in rhizosphere soil of $25 \mathrm{C}-1$ cotton strain was also significantly higher compared to the TH2 strain (Fig. 1), which is different from the research results of Wei et al. after continuous cropping of cotton (Wei and Yu 2018). Previous studies have shown that a reduction in the $\mathrm{OM}$ in the soil caused by continuous cotton cropping is a major factor leading to a significant reduction in the Actinobacteria population (Zhang et al. 2013). However, our research has shown that the TN, OM, Proteobacteria, and Actinobacteria content in the soil increased after continuous cropping of genetically modified cotton. This may be a different effect of genetically modified cotton on the soil.

Among the top 35 genera identified in the soil samples with an abundance of larger than $1 \%$, five were classified in bacterial genera namely Arthrobacter, Blastocatella, unidentified_Gemmatimonadetes, Sphingomonas, and Gemmatimonas (Fig. 2). Two (Arthrobacter and Sphingomonas) of the five among them were significantly different $(P<0.5)$, which was first discovered in the soil of continuous cropping of genetically modified crops. Arthrobacter that belong to gram-positive actinomycetes are found in most of the ecological environments including soil. It is reported that some strains of Arthrobacter have the ability to degrade pesticides, perform nitrogen fixation, and also produce certain beneficial enzymes ( $\mathrm{Fu}$ et al. 2014). As an example, Arthrobacter spp. can degrade the herbicide atrazine that poses a threat to the environment if discharged to waterways. Jiang et al. isolated an Arthrobacter sp. strain HS-G8 that has nitrogen-fixing ability without any nitrogen medium (Jiang et al. 2004). In addition to its nitrogen fixation ability, nitrification and denitrification functions of Arthrobacter are also well reported (Fu et al. 2014). Interestingly, a few species of the Arthrobacter, such as Arthrobacter crystallinis (Camargo et al. 2004) and Arthrobacter chlorophenolum (Westerberg et al. 2000), are also capable of biodegradation. This ability has been exploited for bioremediation of contaminated soil for 


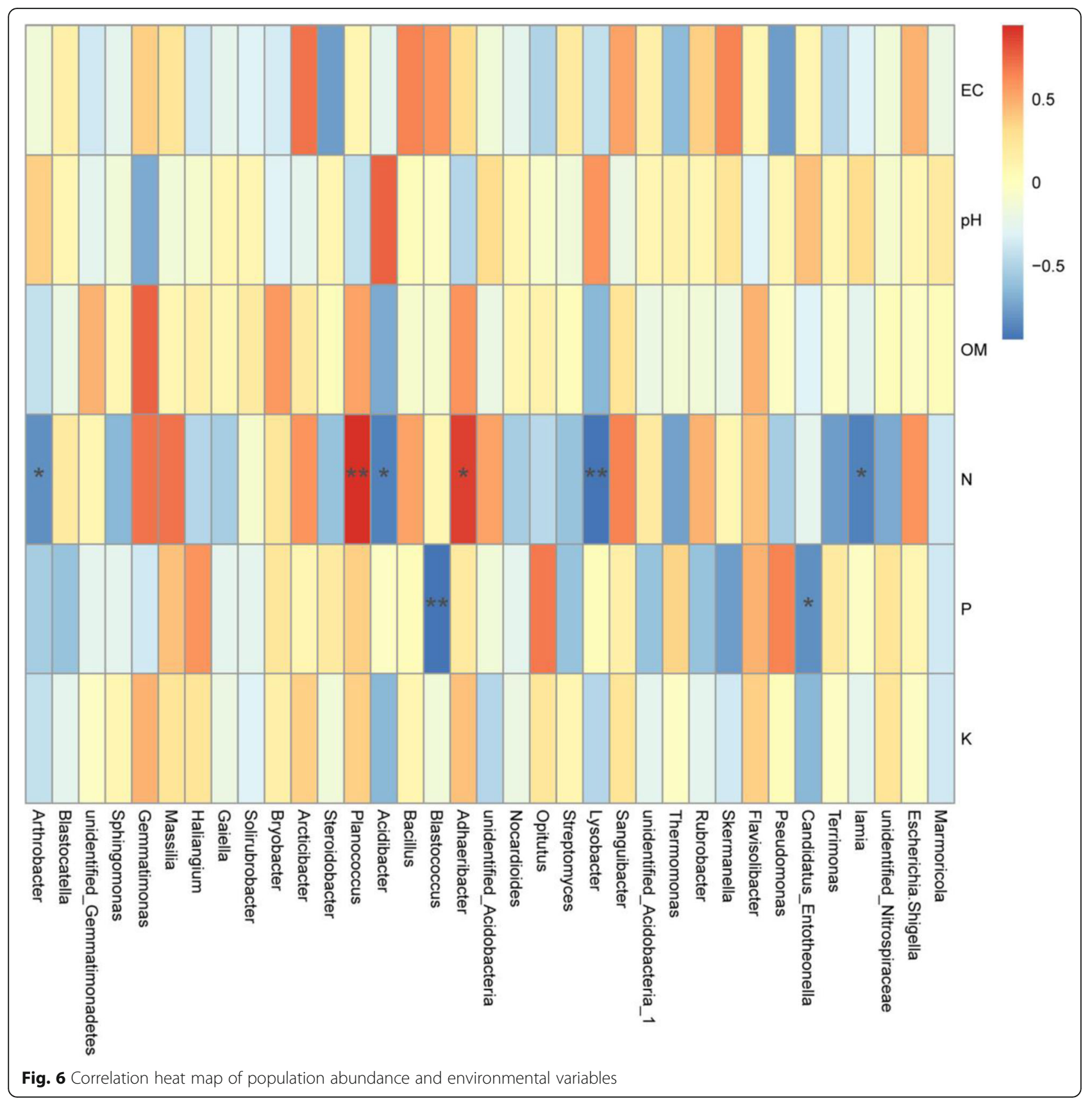

chromium and 4-chlorophenol (Ashvini et al. 2018). Sphingomonas is a gram-negative bacterium that has a special cellular structure. The unique metabolic mechanism and ability to tolerate poor nutrition facilitate their survival to the harshest natural conditions. It has many potential biotechnological applications such as microbe-induced corrosion, production of valuable extracellular polysaccharide polymers, and degradation of refractory organic compounds (White et al. 1996). Previous studies have shown that Sphingomonas can degrade polyethylene glycol (PEG-4000). In combination with other bacteria (known as dual cultures),
Sphingomonas can also degrade PEG6000 (Takeuchi et al. 1993).

According to the UPGMA cluster tree structure and species relative abundance map in the $\beta$-diversity analysis (Fig. 5), there is no significant difference in soil microbial abundance between transgenic cotton and nontransgenic cotton, which is consistent with the results of Shahmoradi et al. (2019). Similarly, many other previous studies revealed that the effect of transgenic crops was minor, transient, or not significant on microbial populations in rhizosphere soil (Turrini et al. 2004; Shen et al. 2006; Sarkar et al. 2009; Velmourougane and Blaise 
2014; Zaman et al. 2015). However, the effects of genetically modified plants on soil microorganisms can be divided into direct effects and indirect effects (Liu et al. 2005). Direct impact will depend on the accumulation of genetically modified protein (Oger et al. 1997). For example, transgene proteins for pest and disease resistance can involve the production of chemical substances that are potentially toxic to non-target soil organisms. In contrast, indirect effects are mediated by changes in plant protein and root exudate composition that arise as a result of modifying the metabolic pathways in the plant tissues. Therefore, the potential risk assessment of transgenic plants still needs a lot of research.

\section{Conclusion}

High-throughput sequencing analysis of rhizosphere soil samples of cotton lines, $\mathrm{TH} 2$ and $25 \mathrm{C}-1$, provided insights about the impact of bacterial communities at the genus level. The results show that Arthrobacter and Sphingomonas might play a role and impact the soil environment positively during continuous cropping of transgenic cotton. According to the physical and chemical properties of the soil, the significant accumulation of total nitrogen in the soil may also be the result of $25 \mathrm{C}-1$ continuous cropping. Furthermore, the microbial community structure in soil was not affected by the cropping of genetically modified cotton and the total microbial population and diversity of experimental fields remain quite similar during the cropping of both genetically modified cotton and non-genetically modified cotton. Though it is difficult to understand the intricate interactions between plant roots and bacteria in the soil environment, this study provides necessary insights into the indirect effects of continuous cropping of genetically modified cotton on soil microorganisms. Cultivation of $C B F 1$ cotton may not pose ecological or environmental risk.

\section{Authors' contributions \\ Wenhui Tian, Xiaolong Yi and Shanshan Liu contributed equally to this work. Aiying Wang and Xiaolong Yi designed the experiment, and Shanshan Liu assisted Xiaolong $Y_{i}$ in completing the experiment. Wenhui Tian , Shanshan Liu and Chao Zhou conducted data analysis. Wenhui Tian wrote and revised the manuscript. All authors read and approved the final manuscript.}

\section{Funding}

This study was financially supported by the Major Project of Genetic Modification (2016ZX08011002).

\section{Availability of data and materials}

The datasets used and/or analyzed during the current study are available from the corresponding author on reasonable request.

\section{Ethics approval and consent to participate}

Ethics approval and consent to participate is not applicable in this study.

\section{Consent for publication}

Consent for publication is not applicable in this study.

\section{Competing interests}

The authors declare that there are no conflicts of interests.

\section{Author details}

${ }^{1}$ College of Life Sciences, Shihezi University, Shihezi 832000, China.

${ }^{2}$ Shandong Industrial Technology Research Institute, Zhejiang University, Shandong 277100, China.

Received: 17 July 2020 Accepted: 6 October 2020

Published online: 29 October 2020

\section{References}

Ashvini C, Ashish P, Rajneesh J, Bobby El, Demario C, Christopher B, Reyna GS, Paul S, John S (2018) Physiological and comparative genomic analysis of Arthrobacter sp. SRS-W-1-2016 provides insights on niche adaptation for survival in uraniferous soils. Genes $9: 31$

Babar U, Nawaz MA, Arshad U, Azhar MT, Ahmad I (2019) Transgenic crops for the agricultural improvement in pakistan: a perspective of environmental stresses and the current status of genetically modified crops. GM Crops Food 2164-5698:5701-2164

Bakker PAHM, Berendsen RL, Doornbos RF, Wintermans PCA, Pieterse CMJ (2013) The rhizosphere revisited: root microbiomics. Front Plant Sci 4:165

Batista K, Giacomini A, Mattos W, Gerdes L, Otsuk I (2015) Changes in the chemical properties of soil cultivated with Brachiaria ruziziensis regarding nitrogen fertilization. Int J Plant Soil Sci 7:160-171

Berendsen RL, Pieterse CM, Bakker PA (2012) The rhizosphere microbiome and plant health. Trends Plant Sci 17:478-486

Berg G, Grube M, Schloter M, Smalla K (2014) Unraveling the plant microbiome: looking back and future perspectives. Front Microbiol 5:148

Bokulich NA, Subramanian S, Faith JJ, Gevers D, Gordon Jl, Knight R, Mills DA, Caporaso JG (2013) Quality-filtering vastly improves diversity estimates from Illumina amplicon sequencing. Nat Methods 10:57-59

Camargo FAO, Bento FM, Okeke BC, Frankenberger WT (2004) Hexavalent chromium reduction by an actinomycete, Arthrobacter crystallopoietes ES 32. Biol Trace Elem Res 97:183-194

DeAngelis KM, Brodie EL, DeSantis TZ, Andersen (2009) Selective progressive response of soil microbial community to wild oat roots. ISME J 3:168-178

Delmont TO, Christopher Q, Shaiber A, Esen ÖC, Lee ST, Rappé MS, McLellan SL, Lücker S, Eren AM (2018) Nitrogen-fixing populations of Planctomycetes and Proteobacteria are abundant in surface ocean metagenomes. Nat Microbiol 3:804-813

Edgar RC (2013) UPARSE: highly accurate OTU sequences from microbial amplicon reads. Nat Methods 10:996-998

Fan QL, Ys L, Wang H et al (2017) Effects of genetically modified cotton on soil bacterial community. Shanxi Agric Sci 45:1124-1127

Fu H, Wei Y, Zou Y, Li M, Wang F, Chen J et al (2014) Research memorandum: de kwetsbaarheid en het betrokken zijn bij ongevallen van chauffeurs van vrachtauto's en personenauto's. Adv Microbiol 04:747-753

Guo JH, Li G, Zhao JN, Yang DL, Xiu WM (2018) Effects of cultivation of droughtresistance and salt-tolerance transgenic cotton on soil nematode community. J Ecol Rural Environ 34:541-546

He X, Xu M, Qiu GY, Zhou J (2009) Use of 15N stable isotope to quantify nitrogen transfer between mycorrhizal plants. J Plant Ecol 2:107-118

Hungria VT, Crusoe EQ, Quero AA, Sampaio M, Maiolino A, Bernardo WM (2013) Guidelines on the diagnosis and management of multiple myeloma treatment: Associação Brasileira de hematologia e hemoterapia e terapia celular project guidelines: Associação Médica Brasileira - 2012. Rev Bras Hematol Hemoter 35:201

Hutchison WD, Burkness EC, Mitchell PD, Moon RD, Leslie TW, Fleischer SJ, Abrahamson M, Hamilton KL, Steffey KL, Gray ME, Hellmich RL, Kaster LV, Wright RJ, Pecinovsky K, Rabaey TL, Flood BR, Raun ES (2010) Areawide suppression of european corn borer with Bt maize reaps savings to non-Bt maize growers. Science 330:222-225

Jepson PC, Croft BA, Pratt GE (2010) Test systems to determine the ecological risks posed by toxin release from Bacillus thuringiensis genes in crop plants. Mol Ecol 3: 81-89.

Jiang Y, Zhou JG, Zhou YP, Liu DL (2004) Isolation and primary identification of a new nitrogng-fixation Arthrobacter strain. J Central China Normal Univ 38:2

Knox OGG, Gupta WSR, Nehl DB, Stiller WN (2007) Constitutive expression of Cry proteins in roots and border cells of transgenic cotton. Euphytica 154:83-90

Koskella JA, Stotzky G (1997) Microbial utilization of free and clay-bound insecticidal toxins from Bacillus thuringiensis and their retention of insecticidal activity after incubation with microbes. Appl Environ Microbiol 63:3561-3568

Lilley AK, Bailey MJ, Cartwright C, Turner SL, Hirsch PR (2006) Life in earth: the impact of GM plants on soil ecology. Trends Biotechnol 24:9-14 
Liu B, Zeng Q, Yan F, Xu H, Xu C (2005) Effects of transgenic plants on soil microorganisms. Plant Soil 271:1-13

Liu R, Jiao T, Li J, Feng Y, Wang A, Wu S, Du L, Jian-bo Z (2019) Ectopic expression of the Pseudomonas aeruginosa KatA gene in cotton improves its drought tolerance and yield under drought stress. Mol Breed 39:117

Lu Y, Wu K, Jiang Y, Guo Y, Desneux N (2012) Widespread adoption of Bt cotton and insecticide decrease promotes biocontrol services. Nature 487:362-365

Magoč T, Salzberg SL (2011) FLASH: fast length adjustment of short reads to improve genome assemblies. Bioinformatics 27:2957-2963

Nie ZN, Mackay AD, Valentine I, Barker DJ, Hodgson J (1997) Influence of pastoral fallow on plant root growth and soil physical and chemical characteristics in a hill pasture. Plant Soil 197:201-208

Oger P, Petit A, Dessaux Y (1997) Genetically engineered plants producing opines alter their biological environment. Nat Biotechnol 15:369-372

Qiao Q, Wang F, Zhang J, Chen Y, Zhang C, Liu G, Zhang H, Ma C, Zhang J (2017) The variation in the rhizosphere microbiome of cotton with soil type, genotype and developmental stage. Sci Rep 7:3940

Randall SK, Yamasaki Y (2016) Functionality of soybean CBF/DREB1 transcription factors. Plant Sci 264:80-90

Raza W, Ling N, Yang L, Huang Q, Shen Q (2016) Response of tomato wilt pathogen Ralstonia solanacearum to the volatile organic compounds produced by a biocontrol strain Bacillus amyloliquefaciens SQR-9. Sci Rep 6:248-256

Riley D, Barber SA (1970) Salt accumulation at the soybean (Glycine max. (L.e merr.) root-soil interface. Soil Sci Soc Am J 34:154-5

Saranga Y, Paterson AH, Levi A (2009) Bridging classical and molecular genetics of abiotic stress resistance in cotton. In: Paterson $\mathrm{AH}$ (ed) Genetics and genomics of cotton, vol 3. Springer, New York, pp 337-352

Sarkar B, Patra AK, Megharaj PM (2009) Assessment of biological and biochemical indicators in soil under transgenic Bt and non-Bt cotton crop in a subtropical environment. Environ Monit Assess 156:595-604

Shahmoradi ZS, Tohidfar M, Marashi H, Shafaroudi SM, Karimi E (2019) Cultivation effect of chitinase-transgenic cotton on functional bacteria and fungi in rhizosphere and bulk soil. Iran J Biotech 17:e1982

Shen RF, Cai H, Gong WH (2006) Transgenic Bt cotton has no apparent effect on enzymatic activities or functional diversity of microbial communities in rhizosphere soil. Plant Soil 285:149-159

Takeuchi M, Kawai F, Shimada Y, Yokota A (1993) Taxonomic study of Polyethylene GlycolUtilizing bacteria: emended description of the genus Sphingomonas and new descriptions of Sphingomonas macrogoltabidus sp. nov., Sphingomonas sanguis sp. nov. and Sphingomonas terrae sp. nov. Syst Appl Microbiol 16:227-238

Trivedi P, He Z, Van Nostrand JD, Albrigo G, Zhou J, Wang N (2012) Huanglongbing alters the structure and functional diversity of microbial communities associated with citrus rhizosphere. ISME J 6:363-383

Turrini A, Sbrana C, Nuti MP, Pietrangeli BM, Giovannetti M (2004) Development of a model system to assess the impact of genetically modified corn and aubergine plants on arbuscular mycorrhizal fungi. Plant Soil 266:69-75

Uroz S, Buée M, Murat C, Frey-Klett P, Martin F (2010) Pyrosequencing reveals a contrasted bacterial diversity between oak rhizosphere and surrounding soil. Environ Microbiol Rep 2:281-288

Van der Heijen MGA, Bardgett RD, van Straalen NM (2008) The unseen majority: soil microbes as drivers of plant diversity and productivity in terrestrial ecosystems. Ecol Lett 11:296

Velmourougane K, Blaise D (2014) Transgenic cotton and its impact on microbial diversity. Springer Int Publ 8:191-204

Velmourougane K, Sahu A (2013) Impact of transgenic cottons expressing CrylAC on soil biological attributes. Plant Soil Environ 59:108-114

Verslues PE, Agarwal M, Katiyar-Agarwal S, Zhu J, Zhu JK (2006) Methods and concepts in quantifying resistance to drought, salt and freezing, abiotic stresses that affect plant water status. Plant J 45:523-539

Wardle DA (2008) A comparative assessment of factors which influence microbial biomass carbon and nitrogen levels in soil. Biol Rev 67:321-358

Wei Z, Yu D (2018) Analysis of the succession of structure of the bacteria community in soil from long-term continuous cotton cropping in Xinjiang using high-throughput sequencing. Arch Microbiol 200:653-662

Westerberg K, Elvang AM, Stackebrandt E, Jansson JK (2000) Arthrobacter chlorophenolicus sp. nov., a new species capable of degrading high concentrations of 4-chlorophenol. Int J Syst Evol Microbiol 50:2083-2092

White DC, Sutton SD, Ringelberg DB (1996) The genus Sphingomonas: physiology and ecology. Curr Opin Biotechnol 7:301

Yang Q, Huang X, Zhao S, Sun W, Yan Z, Wang P, Li S, Wang Z, Zhang S, Liu L, Shuang B (2017) Structure and function of the fecal microbiota in diarrheic neonatal piglets. Front Microbiol 8:502
Zaman M, Mirza MS, Irem S, Zafar Y, Mehboob-ur-Rahman (2015) A temporal expression of CrylAc protein in cotton plant and its impact on soil health. Int J Agric Biol 17:280-288

Zhang L, Wang S (2017) Bacterial community diversity on in-shell walnut surfaces from six representative provinces in China. Sci Rep 7:10054

Zhang W, Long XQ, Huo XD, Chen YF, Lou K (2013) 16S rRNA-based PCR-DGGE analysis of actinomycete communities in fields with continuous cotton cropping in Xinjiang, China. Microb Ecol 66:385-393

\section{Publisher's Note}

Springer Nature remains neutral with regard to jurisdictional claims in published maps and institutional affiliations.

\section{Ready to submit your research? Choose BMC and benefit from:}

- fast, convenient online submission

- thorough peer review by experienced researchers in your field

- rapid publication on acceptance

- support for research data, including large and complex data types

- gold Open Access which fosters wider collaboration and increased citations

- maximum visibility for your research: over $100 \mathrm{M}$ website views per year

At BMC, research is always in progress.

Learn more biomedcentral.com/submissions 